\title{
SOME PROPERTIES OF THE GENERALIZED GAUSSIAN RATIO AND THEIR APPLICATIONS
}

\author{
Zhen-HANG YANG, Bo-YAN XI AND ShEN-Zhou Zheng
}

Abstract. We are devoted to an integral, asymptotic expansion and Maclaurin series representation for the generalized Gaussian ratio, and find their various related properties such as complete monotonicity and some useful inequalities. As applications, several simple approximations for its inverse function are presented, which may be essential to the estimations for the shape parameter of the generalized Gaussian distribution.

Mathematics subject classification (2010): 26A48, 26D05, 33B10, 33B15, 62F99.

Keywords and phrases: Generalized Gaussian ratio, gamma function, completely monotonic function, approximating inequalities, shape parameter.

\section{REFERENCES}

[1] M. Abramowitz and I. A. Stegun (EdS), Handbook of Mathematical Functions with Formulas, Graphs, and Mathematical Tables, National Bureau of Standards, Applied Mathematics Series 55, 9th printing, Washington, 1972.

[2] H. AlZER, On some inequalities for the gamma and psi functions, Math. Comput. 66, 217 (1997), 373-389.

[3] R. D. Atanassov and U. V. Tsoukrovs Ki, Some properties of a class of logarithmically completely monotonic functions, Comptes Rendus de l'Académie Bulgare des Sciences 41, 2 (1988), 21 23.

[4] S. N. Bernstein, Sur les fonctions absolument monotones, Acta Mathematica 52 (1928), 1-66.

[5] P. S. Bullen, Handbook of Means and their Inequalities, Kluwer Academic Publishers, London, UK, 2003.

[6] T. BuRIĆ AND N. ElEzović, Some completely monotonic functions related to the psi function, Math. Inequal. Appl. 14 (2011), 679-691.

[7] J. Bustoz AND M. E. H. Ismail, On gamma function inequalities, Math. Comput. 47, 176 (1986), 659-667.

[8] C. P. Chen AND J. CHOI, Completely monotonic functions related to Gurland's ratio for the gamma function, Math. Inequal. Appl. 20, 3 (2017), 651-659.

[9] J. A. Domínguez-Molina, G. GonzÁlez-Farías and R. M. Rodríguez-Dagnino, A practical procedure to estimate the shape parameter in the generalized Gaussian distribution, Technique Report, 1-01-18(2001), http://www. cimat.mx.

[10] G. Gonzalez-Farias, J. A. D. Molina And R. M. Rodriguez-Dagnino, Efficiency of the approximated shape parameter estimator in the generalized Gaussian distribution, IEEE Transactions on Vehicular Technology 58, 8 (2009), 4214-4223.

[11] J. GURLAND, An inequality satisfied by the gamma function, Skandinavisk Aktuarietidskrift 39 (1956), 171-172.

[12] M. E. H. Ismail, L. Lorch And M. E. Muldoon, Completely monotonic functions associated with the gamma function and its q-analogues, J. Math. Anal. Appl. 116, 1 (1986), 1-9.

[13] J. D. KečKIĆ And P. M. VAsić, Some inequalities for the gamma function, Publ. Inst. Math. Belgrade 11, 25 (1971), 107-114.

[14] R. KRUPIŃSKI AND J. PURCZYŃSKI, Approximated fast estimator for the shape parameter of generalized Gaussian distribution, Signal Processing 86 (2006), 205-211. 
[15] R. KRUPIŃS KI, Approximated fast estimator for the shape parameter of generalized Gaussian distribution for a small sample size, Bulletin of the Polish Academy of Sciences Thchnical Sciences 63, 2 (2015), DOI: 10.1515/bpasts-2015-0046.

[16] S. G. MALLAT, A theory of multiresolution signal decomposition: the wavelet representation, IEEE Transactions on Pattern Analysis and Machine Intelligence 11 (1989), 674-693.

[17] M. MerkLE, Gurland's ratio for the gamma function, Computers \& Mathematics with Applications 49, 2-3 (2005), 389-406.

[18] F. MULER, Distribution shape of two-dimensional DCT coefficients of natural images, Electronics Letters 29 (1993), 1935-1936.

[19] F. QI, A class of logarithmically completely monotonic functions and application to the best bounds in the second Gautschi-Kershaw's inequality, J. Comput. Appl. Math. 224 (2009), 538-543.

[20] F. QI, Bounds for the ratio of two gamma functions, J. Inequal. Appl. 2010 (2010), Art. ID 493058.

[21] F. QI, A double inequality for ratios of the Bernoulli numbers, Available online at http://www.researchgate.net/publication/264418049 (2014).

[22] F. QI, Bounds for the ratio of two gamma functions: from Gautschi's and Kershaw's inequalities to complete monotonicity, Turkish J. Anal. Number Theory 2, 5 (2014), 152-164.

[23] F. QI AND B. N. GuO, Complete monotonicities of functions involving the gamma and digamma functions, RGMIA Research Report Collection 7, 1 (2004), 63-72.

[24] F. QI AND Q. M. LUO, Bounds for the ratio of two gamma functions: from Wendel's asymptotic relation to Elezović-Giordano-Pečarić's theorem, J. Inequal. Appl. 2013 (2013), Art. ID 542.

[25] R. SChILling, R. SONG AND Z. VONDRAČEK, Bernstein functions: Theory and Applications, Studies in Mathematics 37, de Gruyter, Berlin, 2010.

[26] K. SHARIFI AND A. L. GARCIA, Estimation of shape parameter for generalized Gaussian distribution in subband decompositions of video, IEEE Transactions on Circuits and Systems for Video Technology 5 (1995), 52-56.

[27] M. VAranasi And B. A. Zhang, Parametric generalized Gaussian density estimation, Journal of the Acoustical Society of American 86 (1989), 1404-1415.

[28] E. T. WhitTaker and G. N. Watson (Eds), A Course in Modern Analysis, Cambridge University Press, 4th ed, Cambridge, UK, 1990.

[29] D. V. Widder(Eds), The Laplace Transform, Princeton University Press, Princeton, 1946.

[30] Z. H. YANG, Approximations for certain hyperbolic functions by partial sums of their Taylor series and completely monotonic functions related to gamma function, J. Math. Anal. Appl. 441 (2016), 549-564.

[31] Z. H. YANG AND J. F. Tian, Optimal inequalities involving power-exponential mean, arithmetic mean and geometric mean, J. Math. Inequal. 11, 4 (2017), 1169-1183.

[32] Z. H. YANG AND J. F. TIAN, A comparison theorem for two divided differences and applications to special functions, J. Math. Anal. Appl. 464 (2018), 580-595.

[33] Z. H. YANG AND J. F. TIAN, A class of completely mixed monotonic functions involving the gamma function with applications, Proc. Amer. Math. Soc. 146, 11 (2018), 4707-4721.

[34] Z. H. YANG AND S. Z. ZHENG, Monotonicity of a mean related to polygamma functions with an application, J. Inequal. Appl. 2016 (2016), Art. ID 216.

[35] Z. H. YANG AND Z. S. ZHENG, Complete monotonicity involving some ratios of gamma functions, J. Inequal. Appl. 2017 (2017), Art. ID 255.

[36] Z. H. YANG ANG S. Z. Zheng, The monotonicity and convexity for the ratios of modified Bessel functions of the second kind, Proc. Amer. Math. Soc. 145, 7 (2017), 2943-2958.

[37] Z. H. YANG ANG S. Z. Zheng, Monotonicity and convexity of the ratios of the first kind modified Bessel functions and applications, Math. Inequal. Appl. 21, 1 (2018), 107-125. 